\title{
LA TENSIÓN EPISTEMOLÓGICA ENTRE LA FILOSOFÍA DEL DERECHO Y LA TEORÍA JURÍDICA. HACIA UNA TEORÍA CRÍTICA DEL DERECHO
}

\author{
OSCAR MEJÍA QUINTANA
}

Universidad Nacional de Colombia

(c) 


\title{
LA TENSIÓN EPISTEMOLÓGICA ENTRE LA FILOSOFÍA DEL DERECHO Y LA TEORÍA JURÍDICA. HACIA UNA TEORÍA CRÍTICA DEL DERECHO
}

\begin{abstract}
Resumen: este escrito ilustra la diferencia que tiene que hacerse entre la filosofía del derecho, proveniente de una tradición filosófica, y la teoría jurídica, referida a una tradición jurídica. Muestra el proceso de descomposición que sufre la filosofía del derecho con el positivismo jurídico y la consolidación de la teoría jurídica a partir de ello. La teoría de la justicia rawlsiana y la teoría discursiva habermasiana replantean el estatuto de ambas disciplinas para ambientar la consolidación de una teoría crítica del derecho donde filosofía del derecho, teoría jurídica e, incluso, sociología jurídica puedan complementarse recíprocamente.
\end{abstract}

Palabras clave: iusnaturalismo, filosofía del derecho, teoría jurídica, positivismo, filosofía de la justicia, sociología del derecho, autopoiesis, interpretación, teoría crítica del derecho.

\section{EPISTEMOLOGICAL TENSION BETWEEN THE PHILOSOPHY OF LAW AND LEGAL THEORY. TOWARDS A CRITICAL THEORY OF LAW}

\begin{abstract}
This paper illustrates the difference has to be made between the philosophy of law, from a philosophical tradition, and legal theory, based on a legal tradition. It shows the decomposition process that suffers the philosophy of law with legal positivism and consolidation of legal theory from it. The theory of justice Rawls and Habermas's discourse theory rethink the status of both disciplines to acclimate the consolidation of a critical theory of law where philosophy of law, legal theory and even legal sociology can complement each other.
\end{abstract}

Keywords: natural law, philosophy of law, legal theory, positivism, philosophy of justice, sociology of law, autopoiesis, interpretation, critical theory of law.

Fecha de recepción: Mayo 15 de 2016

Fecha de aceptación: Agosto 22 de 2016

Forma de citar (APA): Mejía, O. (2016). La tensión epistemológica entre la filosofía del derecho y la teoría jurídica. Hacia una teoría crítica del derecho. Revista Filosofía UIS, 15 (1), 107-136, doi: http://dx.doi.org/10.18273/revfil.v15n1-2016005

Forma de citar (Harvard): Mejía, O. (2016). La tensión epistemológica entre la filosofía del derecho y la teoría jurídica. Hacia una teoría crítica del derecho. Revista Filosofía UIS, 15 (1), 107-136.

Oscar Mejía Quintana: colombiano. Profesor Universidad Nacional de Colombia. Postdoctor en Filosofía (Filosofía del Derecho), Universidad Nacional de Colombia.

Correo electrónico: oemejia@hotmail.com

* Artículo de reflexión. 


\section{LA TENSIÓN EPISTEMOLÓGICA ENTRE LA FILOSOFÍA DEL DERECHO Y LA TEORÍA JURÍDICA. HACIA UNA TEORÍA CRÍTICA DEL DERECHO}

\section{Introducción}

La modernidad temprana culmina con los dos modelos clásicos de filosofía del derecho de Kant y Hegel, el primero sintetizando toda la teoría del contrato social y el segundo desarrollando la más aguda crítica al mismo. A partir de allí, el siglo XIX evidencia un proceso de ruptura con la filosofía del derecho del que va surgiendo lentamente la teoría jurídica como disciplina autónoma y que culmina con la Teoría Pura del Derecho de Kelsen en el primer cuarto del siglo XX dando nacimiento a una disciplina independiente de la filosofía del derecho, con un estatuto epistemológico y unas problemáticas propias.

El famoso manual de Gustav Radbruch, que data de 1948, pone ya de presente el drama de la filosofía del derecho. Los problemas propios de la disciplina eran ya, para el autor, la humanidad como concepto jurídico, el derecho social, la democracia, el derecho internacional y el derecho supralegal. Un catálogo de problemas que, desde mucho antes, se había convertido en objeto de la filosofía política (la legitimidad), la teoría jurídica (la validez) y la sociología del derecho (la eficacia) (Radbruch, 1993, pp.153-180).

Ese desdibujamiento de su problemática particular, iniciado por la autonomía que desde el siglo XIX va adquiriendo la teoría jurídica frente a la filosofía del derecho y que el positivismo finalmente consagra, justifica el proyecto de reconstruir, de manera integral y vinculatoria, el estatuto epistemológico que la filosofía del derecho podría tener en nuestros días. 
La hipótesis de trabajo que este escrito busca ilustrar es la siguiente:

La distinción epistemológica entre filosofía del derecho y teoría jurídica se justifica históricamente en cuanto la primera responde a una tradición filosófica, que alcanza su apogeo con lo modelos de Kant y Hegel, mientras que la segunda se inscribe en una tradición jurídica (que, análogamente, se consagra a partir de Kelsen), siendo cada cual una disciplina autónoma que no puede confundirse con la otra pues cada una posee dominios epistémicos diferentes. Sin embargo, el estatuto epistemológico de la primera puede ser reconstruido en diálogo con la teoría jurídica y la teoría constitucional, relacionando transdisciplinariamente las tres problemáticas de la legitimidad, la validez y la eficacia desde una teoría crítica del derecho que permita articular una visión sistemática, cuestionadora y totalizante del fenómeno jurídico en su complejidad integral.

El presente ensayo busca contextualizar históricamente el proceso de ruptura y desdibujamiento epistemológico de la filosofía del derecho que Gregorio Robles ya había puesto de presente, recogiendo la sentencia de Ralf Dreir en Alemania: "La filosofía del derecho ha muerto, viva la teoría del derecho" y que a su vez aquel consagraba al afirmar: $<<$ La crisis de la denominación "filosofía del derecho" responde a la crisis propia del positivismo ontologista, sobre el cual aquella cimentó su existencia. Con la expresión "teoría del derecho" se abre una nueva vía que supone un cambio de paradigma en el pensamiento jurídico >> (Robles, 1993, p.16).

Pero, en nuestro caso, apartándose enfáticamente de su propuesta de reducir la filosofía del derecho a teoría jurídica y esta última a una teoría analítica del lenguaje jurídico: "Dicha propuesta se resume así: la filosofía del derecho —o, como preferimos llamarla, la teoría del derecho- es análisis del lenguaje de los juristas" (17). Y, por el contrario, poniendo de presente que la reconstrucción del estatuto de la filosofía del derecho pasa, mejor, por la fundamentación de una teoría crítica del derecho como bien puede inferirse de los planteamientos de Rawls y, particularmente, Habermas.

En ese propósito, buscará rastrear las raíces de la problemática en la discusión de la modernidad temprana entre el contractualismo, que culmina con Kant y su polémica con Hegel (1), y el proceso posterior, a partir de la tensión del siglo XIX entre el marxismo, y su cuestionamiento radical al derecho, y las diferentes escuelas que ya perfilan la teoría jurídica autónoma (2), proceso que se acelera con el surgimiento del positivismo contemporáneo, donde la teoría jurídica, con Kelsen y Hart, le arrebata definitivamente su fundamento epistemológico a la reflexión iusfilosófica (3), y que el planteamiento de Niklas Luhmann cierra con su concepción de un sistema jurídico autopoiético donde la reflexión iusfilosófica es concebida como externa, incluso disfuncional, al ordenamiento (4). 
Enseguida, se aborda el paradigma interpretativo, en sus variantes de Dworkin y Alexy, y la forma en que, paradójicamente, aceleran el desdibujamiento de la filosofía del derecho al reducirla a teoría jurídica (5) para, finalmente, a partir de los presupuestos sugeridos por la filosofía de la justicia de Rawls (6) y la teoría crítica del derecho de Habermas (7), enmarcada en la tradición de las teorías críticas del derecho, sugerir los elementos desde los cuales reconstruir el estatuto epistemológico de la filosofía del derecho contemporánea, en diálogo con la teoría jurídica y la teoría constitucional recíprocamente.

\section{El Momento de la Filosofía del Derecho}

\subsection{La Disputa con el Contractualismo}

En efecto, la filosofía del derecho de la modernidad temprana, como queda claramente consignado en Hobbes, se orienta hacia una reflexión sobre la relación entre legitimidad y legalidad, mostrando cómo el orden legal depende de unos factores de legitimidad, la paz y la vida, que al mismo tiempo son indicadores de la eficacia del estado. Pero ya aquí su estatuto comienza a problematizarse en la medida en que el problema de la legitimidad y el problema de la eficacia hacen referencia, el uno a una esfera política y el otro a una esfera social que, podría sospecharse, no son directamente de su objeto de investigación como más claramente parecerían serlo de la filosofía política y la sociología del derecho, esta última todavía embrionaria, por supuesto, en tiempos de Hobbes.

La confusión se agudiza cuando, con Locke, los factores de legitimidad quedan subsumidos totalmente a la legalidad de los procedimientos. El contractualismo lockeano, prefigurando la autorreferencialidad luhmanniana, reduce a la legalidad procedimentalizada, tanto la legitimidad como la eficacia del sistema. El procedimiento concebido para salir del estado de guerra y constituir el contrato social que da nacimiento a la sociedad política define desde ese momento el criterio de legitimidad exclusivo, además del de la propiedad que por ser básico es simplemente un factum innegociable y, si se quiere, un indicador de eficacia del sistema, sin que las principios ni leyes de naturaleza, como las hobbesianas, determinen o no la justificación política o moral del mismo. Filosofía política, filosofía del derecho y sociología jurídica quedan amalgamadas en el procedimiento que es el que, en últimas, en términos políticos, jurídicos y sociales determina la legitimidad, la validez y la eficacia del sistema.

Rousseau no aporta mucho a la problemática salvo porque su categoría de voluntad general como expresión de un cuerpo colectivo moral y su inclinación al modelo de política antiguo, enraizado en el entramado de las virtudes, subsume otra dimensión, complejizando la problemática: la moral, que hasta ese momento había podido escaparse de la relación, súbitamente queda amarrada a esa 
voluntad general que, en cuanto sociedad política, termina igualmente anclada a los procedimientos jurídico-políticos del sistema que a la postre serían los de la democracia liberal (Mejía, 1997, pp.13-35).

Con Kant se produce, sin duda, una delimitación de tres de las esferas anotadas: la moral, el derecho y la política quedan autonomizadas en sus esferas y estatutos epistemológicos respectivos, evidenciándose, sin embargo su condicionalidad recíproca. Pero el énfasis sigue dándosele a la moral en la medida en que la deducción trascendental de la idea del derecho y la política se deriva de los presupuestos de universalidad, autonomía y libertad determinados por la primera ${ }^{1}$.

Hegel, por su parte, no avanza sustancialmente en lo que a la filosofía del derecho se refería. La estructura de la misma pretende superar la formalidad del derecho moderno y la vaciedad de la moral kantiana en la figura de la eticidad que el estado lleva a su máxima expresión. El estado subsume la dimensión jurídica e, igualmente la dimensión política, en la perspectiva de interpretar y preservar el ethos que necesariamente lo origina y le confiere su razón última (Palmier, 1977, pp.81-100) $)^{2}$.

Aquí se presentan dos lecturas opuestas, ambas en el marco de la modernidad, de la relación trilemática entre legitimidad, validez y eficacia. En Kant, la justificación moral, en términos de universalidad, autonomía y libertad, fija los límites de la validez del derecho y de la legitimidad del contrato social: el derecho tiene que preservar la frontera infranqueable de las libertades subjetivas y la política tiene que asumir el consenso universal como idea normativa de su realización. La eficacia del ordenamiento parece quedar sujeta a tales condiciones. En Hegel, por el contrario, la relación queda anclada a la preservación del ethos: el derecho será valido y la política legitima en la medida en que la eticidad, a través del estado, respete las protoformas del ethos y la identidad de las comunidades. La eficacia del ordenamiento queda, igualmente, sujeta a esa traducción jurídicopolítica que el estado hace de la identidad ética de un pueblo.

La pregunta que se impone en torno al estatuto epistemológico de la filosofía del derecho que nos convoca es la de la lectura que cada una de estas interpretaciones supone. En Kant es claro que esta queda restringida al fenómeno jurídico en términos positivos mientras que en Hegel adquiere un carácter más totalizante, congruente con esa inclinación aristótelica de su óptica (Aristóteles, 1987), como se deduce fácilmente de la estructura misma de su Filosofia del Derecho (1968).

\footnotetext{
${ }^{1}$ Ver: (Cortina, 1989); (González, 1984).

2 Ver: (Palmier, 1977); (Findlay, 1969) y (Marcuse, 1976).
} 
En la primera, se anticipa ya el perfil autorreferente de la teoría jurídica contemporánea y en la segunda se mantiene el perfil totalizante pero problemático del modelo de la antigüedad. La kantiana prefigura, así, la validez como problemática epistemológica central de la teoría jurídica y la hegeliana el de una relación total pero compleja, en términos epistemológicos, entre las tres dimensiones.

\subsection{Entre la validez y la sospecha}

El siglo XIX constituirá una paradójica bifurcación de toda esta reflexión. De una parte, Marx, desde la economía política, va plantear uno de los más radicales cuestionamientos sobre el derecho y la política de toda la modernidad. Y, de otra, la teoría del derecho, en el marco de la tensión entre los modelos kantiano y hegeliano, comienza claramente a perfilarse y a romper el cordón umbilical con la filosofía del derecho.

En una primera bifurcación, las dos posturas, en especial la hegeliana, serán confrontadas por Marx, denunciando la abstracción que ambas hacen de las condiciones materiales que la validez, la legitimidad y la eficacia suponen, es decir, de la existencia de esquemas de dominación que se imponen, ya por la fuerza, ya por la ideologización. El radical cuestionamiento marxista sobre lo jurídico y lo político y, por tanto, sobre la validez del sistema jurídico, la legitimidad del ordenamiento político y la eficacia del sistema social, en general, deriva en su vertical posición frente a los derechos humanos y la democracia en el marco del capitalismo como productos e instrumentos de la burguesía dominante para preservar su dominio ${ }^{3}$.

La introducción a la Crítica de la Filosofía del Derecho de Hegel (1978) anticipa la intuición que Pashukanis, retomando a Lenin, llevará a sus consecuencias naturales: la filosofía del derecho no tiene ningún estatuto epistemológico. Solo puede concebirse como crítica de la economía política o, a lo sumo, como crítica ideológica del derecho y, por extensión, de la política. El marxismo estructuralista de Poulantzas y Althusser será el que vendrá a resolver esa tensión de la tradición marxista poniendo de presente que la figura mas distorsionadora de la ideología burguesa es, precisamente, la ideología jurídico-política que alcanza su máxima y mas irónica expresión en la teoría jurídica que trata de dar razón de ello ${ }^{4}$.

La segunda bifurcación nos pone en dirección de la teoría jurídica contemporánea a partir de la tensión entre las dos lecturas sugeridas por Kanty Hegel, respectivamente. En la línea kantiana, aunque no siempre directamente derivada de su postura, se inscribirán escuelas como la de la Exégesis, y la Jurisprudencia

Como se puede ver en: (Marx, 1973, pp. 516-520); (Pashukanis, 1976, pp. 37-51); (Conde, 1989); (Dreier, et al. 1984); (Mazurek y Kaufmann, A., 1992, pp. 333-348).

${ }^{4}$ Ver: (Poulantzas, 1976); (Althusser, 1974). 
de Conceptos, mientras que la matriz hegeliana será indudablemente recogida por la Escuela Histórica del Derecho, así como ciertas mixturas, que de la misma manera pondrán su énfasis ya en aspectos universales ya en contextuales, como la Jurisprudencia de Intereses y la Escuela del Derecho Libre ${ }^{5}$.

En todas ellas la tensión entre universalidad y eticidad se resimboliza de diferente manera, definiendo la validez del derecho ya por su identidad con una o con otra. Pero lo determinante será que la reflexión iusfilosófica, centrada en consideraciones extrasistémicas, más generales, va dando paso a un pensamiento sistemático sobre el derecho desde una perspectiva que en lo esencial se estructura de manera intrasistémica. Por supuesto, ello genera un abandono progresivo de los problemas clásicos de la filosofía del derecho como eran el de la relación entre legitimidad y legalidad o el de la obediencia o desobediencia del derecho que hasta Kant y Hegel podían rastrearse.

El eje se desplaza del entorno del derecho, ya sea moral o político, al derecho como sistema, lo cual ya era un camino preparado, en todo caso, tanto por Kant como por Hegel. Esta tendencia encuentra en la Escuela del Realismo Jurídico, ya fuera en su versión escandinava ya en la norteamericana, su consagración definitiva en cuanto, pese a la apariencia contraria, es el juez y, en particular, la decisión judicial la clave de la validez del derecho. La teoría jurídica logra romper definitivamente con la filosofía del derecho, no sin costos por supuesto, como dramáticamente se vería después, y, simultáneamente, la filosofía del derecho pierde su perfil al no ser claro el problema epistemológico que orienta su reflexión (Hierro, 1996, pp.77-86).

\section{El Momento de la Teoría Jurídica}

\subsection{Positivismo y Teoría Jurídica}

En efecto, si la validez deviene el problema de la teoría jurídica naciente y la legitimidad lo es de la filosofía política, así como la eficacia el de la sociología del derecho, ¿cuál es el problema específico de la filosofía del derecho, desde dónde estructurar su estatuto epistemológico? Los manuales de filosofía del derecho de la primera mitad del siglo XX, cuya incidencia en muchas latitudes se mantiene hasta hoy, centran el eje de reflexión de la filosofía del derecho en torno a tres disciplinas filosóficas: la epistemología, la ontología y la axiología del derecho. La primera determinando el objeto de la ciencia jurídica (teoría del conocimiento jurídico que, en algunos casos, se complementa con una teoría de la argumentación jurídica); la segunda, la estructura del ser del fenómeno jurídico (concepto del derecho) y la tercera proyectando el deber ser del derecho como sistema normativo (teoría de la justicia).

${ }^{5}$ Ver, en general, (Hernández, 1989). 
Las variaciones y originalidades se daban en torno a cual subdisciplina se subordinaban las otras. Arthur Kaufmann subdivide, precisamente, la filosofía del derecho en ontología (estudio del mundo como objetividad), epistemología (estudio del mundo como subjetividad) y filosofía de la existencia (estudio del mundo como autorrealización). Del Vecchio, por su parte, divide la filosofía del derecho en lógica (la cual define el derecho en su universalidad), fenomenología (la cual investiga los caracteres generales de su desarrollo) y deontología (la cual valora según el ideal de justicia trazado por la razón pura) (Kaufmann, 1999, pp.37-43; del Vecchio, 1991, pp.275-289).

En las tres perspectivas se superponían aspectos de legitimidad, validez y eficacia sin que quedaran delimitados con precisión los cruces epistemológicos que a su vez se producían con la filosofía política, la teoría del derecho y la sociología jurídica, sin hablar de la filosofía moral que, en la dimensión axiológica, también entraba a jugar. En Bobbio, por ejemplo, la filosofía del derecho se subdivide en una teoría de la ciencia jurídica, una teoría del derecho y una teoría de la justicia, siendo esta última la principal y teniendo como objetos de estudio la relación entre legitimidad y legalidad, el consenso social y la fundamentación del estado de derecho. Es decir, el espectro de problemas iusfilosóficos de la modernidad temprana (Citado por Férnandez, 1991, p. 27).

En el marco de conceptualizaciones análogas sobre el objeto de la filosofía del derecho, herencia indirecta de discusión moderno-temprana, va surgiendo la teoría pura del derecho de Kelsen y la definición del positivismo jurídico como la primera y, quizás, más importante escuela teórico-jurídica. Kelsen define la validez como un problema exclusivo de la teoría jurídica precisamente para deslindarlo de dos problemas que a su modo de ver no tenían, al menos directamente, que ver con su campo de conocimiento: el de la legitimidad y el de la eficacia.

La pregunta por la validez del ordenamiento como pregunta esencial de la teoría jurídica es la pregunta por las condiciones de posibilidad del conocimiento jurídico. En la línea kantiana, Kelsen parte de dos a priori del conocimiento del fenómeno jurídico: el ordenamiento como tal que preexiste a la norma particular y en el cual esta se inscribe y la norma fundamental que, en últimas, es la condición incondicional de la validez de todo el ordenamiento ${ }^{7}$. Si bien las relaciones con las esferas de la legitimidad y la eficacia siguen siendo complejas en cuanto la norma fundamental presupone un contenido axiológico que solo hasta el final de su vida Kelsen acepta y de que la mínima eficacia del sistema es un requisito de su validez general, el autor logra deslindar definitivamente la teoría jurídica de la filosofía del derecho, definiendo su problemática específica aunque, obviamente, originando otros problemas no menos decisivos para el desarrollo de la tradición positivista (Kelsen, 1997, pp. 201-232).

${ }^{6}$ Véase aplicado al contexto colombiano: (Naranjo, 1992).

${ }^{7}$ Ver: (Kelsen, 1996). 
Pero con la teoría pura kelseniana el derecho rompe definitivamente su paternidad con la filosofía del derecho, por un lado, y con la sociología del derecho por otro tomando distancia frente a dos escuelas que posteriormente tendrían que acomodarse a esta nueva geografía epistemológica: el iusnaturalismo y el realismo jurídico que eran las puntas de lanza de los resabios de la filosofía del derecho de la modernidad temprana, cuando no de la premodernidad, y de la nueva sociología del derecho.

Una interesante disgregación del positivismo, en una variante más hegeliana que kantiana, la constituye el contemporáneo y contradictor de Kelsen, Carl Schmitt. Su implacable crítica de la democracia liberal, muestra de una parte cómo la decisión del soberano desborda, en un momento dado, la necesidad de legitimación democrática de la sociedad y, de otra, cómo el derecho positivo, sin dejar de serlo, es la expresión de un orden concreto, en una gradación de innegable influencia hegeliana que va desde el momento óntico, la vida real de un pueblo, pasando por el lógico, la idea de derecho derivada de lo anterior, hasta el nivel ontológico concreto del derecho positivo y, finalmente, el práctico concreto de la decisión judicial. Schmitt sintetiza con su fórmula dos siglos de discusión iusfilosófica asimilándola, como Kelsen, a la teoría del derecho ${ }^{8}$.

Aunque no sea de buen recibo por los juristas adeptos de la filosofía, lo cierto es que en este momento la teoría del derecho se separa de la filosofía del derecho y conquista su madurez epistemológica. Conquista que para la segunda consagra, al mismo tiempo, su limbo epistemológico, en la medida en que pierde definitivamente los contornos específicos, no de un objeto, sí de un problema disciplinario particular. Desde ese momento, en realidad, la teoría del derecho es el ámbito de reflexión propio del derecho como disciplina y la filosofía del derecho deviene un fantasma epistemológico sin problemática propia, salvo cuando los juristas las identifican con la teoría jurídica y los filósofos con la historia de la filosofía.

Hart va a tratar de flexibilizar la teoría jurídica cuyos postulados kelsenianos de pureza metódica y neutralidad axiológica habían desarmado al derecho de la posibilidad de corrección frente a sus propios excesos. En ese memorable capítulo inicial de su obra cumbre, Hart plantea las perplejidades de la teoría jurídica, dos de las cuales son precisamente no reducir el derecho a órdenes respaldadas por amenazas y la necesidad de replantear la relación entre derecho y moral (Hart, 1995, pp.125-137).

Si bien Hart introduce en los capítulos finales una reflexión definitiva sobre la necesidad de congruencia entre el sistema jurídico y el sistema moral, fundamentándose los dos en un derecho mínimo natural común, mantiene

$\overline{{ }^{8} \operatorname{Ver}(\text { Schmitt, 1996). }}$

Revista Filosofía UIS, Vol. 15, No. 1, enero-junio de 2016 pp. 107-136 
- pese a su oposición a Kelsen con la regla de reconocimiento que pretende contrastar la ambigüedad de la norma fundamental — el estatuto epistemológico propio de la teoría jurídica contemporánea (Dworkin y Hart, 1997).

Pero aquí se impone una aclaración que será clave en el desarrollo de la teoría jurídica hacia el futuro. La estructura epistemológica que se deriva del planteamiento hartiano trifurca la teoría jurídica en tres proyecciones: ¿qué es el derecho?, ¿cómo funciona el derecho? y ¿qué debe ser el derecho?; con lo cual se anticipa el paso cualitativo que la teoría jurídica daría en relación al conjunto de la filosofía práctica contemporánea que queda anclada en la perspectiva monoproblemática de sus disciplinas particulares. La teoría jurídica subsume así, desde su propia óptica, las problemáticas de la legitimidad y la eficacia y se inicia un proceso de ampliación y definición de su estatuto epistemológico que, más adelante, Robert Alexy pondrá en evidencia: la validez del derecho no solo es jurídica sino que deviene también social y moral.

\section{El Momento de la Sociología Jurídica}

\subsection{Luhmann: desdibujamiento de la filosofía del derecho}

El paradigma autopoiético o autorreferencial concibe el derecho, la política y la moral como sistemas sociales autonomizados entre sí, sin otro tipo de comunicación que el sistémico o funcional y constituye una radicalización del iuspositivismo kelseniano, resimbolizando la validez jurídica en términos de una concepción autorreferente del sistema jurídico9. Podría parecer que Luhmann reduce de nuevo la validez del derecho a una sola dimensión pero es todo lo contrario. La prioridad de los sistemas sociales, incluido el jurídico, no es ya la adaptación a la complejidad del entorno sino a su propia complejidad, lo que constituye un giro radical en el imperativo del derecho en cuanto el eje de sus decisiones no proviene del entorno social sino que se estructura a partir de sus propias capacidades y posibilidades internas.

La idea de Luhmann es que la complejidad social se reduce constriñendo la complejidad interna del sistema jurídico. La apertura cognitiva ante el entorno supone una clausura normativa del sistema jurídico, en el sentido de que el código binario propio al derecho es el que garantiza que la complejidad social se traduzca al lenguaje jurídico y se resuelva en términos jurídicos y no sociales. El derecho reduce complejidad social en términos de validez jurídica, no de eficacia social o legitimidad política.

${ }_{9}^{9}$ Ver: (Martínez, 1992, pp. 82-94); (Izuzquiza, 1990, pp. 292-298). 
Pero eso no significa que las dimensiones de eficacia del sistema jurídico o legitimidad del mismo no sean contempladas por el derecho en términos sistémicos. La validez jurídica implica, necesariamente — so pena de caer en un formalismo que solo podría conducir al derrumbamiento del sistema-, una reducción eficaz de la complejidad social y, obviamente, connota una dimensión de legitimidad que el derecho resuelve en términos funcionales.

¿Qué consecuencias tiene ello para la filosofía del derecho? Para Luhmann, la teoría jurídica es la llamada a observar los procesos sistémicos del derecho en orden a desparadojizar y destautologizar los mismos. En efecto, la adaptación del sistema a sí mismo, y por ende al entorno, y la legitimidad que se puede derivar de su capacidad de adaptación supone la autobservación del sistema. Tal autobservación es la que puede evitar la paradoja sistémica, es decir, la imposibilidad de que el sistema no logre captar su complejidad y reducirla. La función de la teoría jurídica es evitar esto, observando adecuadamente al sistema y propiciando su adaptación a sí mismo.

La teoría jurídica garantiza, así, el cierre autopoiético del sistema y la adaptación a su propia complejidad. Sin embargo, esta observación de primer orden tiene que complementarse con una observación de segundo orden: tal función sistémica es llevada a cabo, según Luhmann, por la sociología del derecho (1985, pp. 274-288). Esta observación complementa la de la teoría jurídica, pero igualmente desde una óptica intrasistémica y no extrasistémica, como la sociología jurídica la ha planteado tradicionalmente, propiciando con esto una complejización excesiva del sistema jurídico ${ }^{10}$.

La sociología del derecho es una observación de la observación: observa la relación de la teoría jurídica con la complejidad del sistema jurídico. En últimas es la garantía del cierre autopoiético del sistema, señalando el peligro potencial de importación de normas externas al derecho, calibrando la función límite entre apertura cognitiva y cierre normativo del sistema jurídico. Tal observación asegura la validez y unidad del sistema como función autopoiética y no como consecuencia del entorno, y, por tanto, el carácter circular, simétrico y recursivo de su autopoiésis (Luhmann, 1997, pp.87-119).

En ese marco la filosofía del derecho no cumple ninguna función, más que, si se quiere, retórica. Constituye un elemento externo al sistema jurídico, podríamos calificarlo casi de moral, y, por tanto, potencialmente peligroso en la medida en que puede generar un exceso de complejidad al interior del sistema jurídico, es decir, de contingencia no estructurada que no se ciñe al código binario del lenguaje legal.

\footnotetext{
${ }^{10}$ Ver: (Giménez, 1993, pp. 294-335).
} 
La filosofía del derecho no solo deja de tener lugar en el planteamiento autopoiético sino que, incluso, es una dimensión extraña a la dinámica sistémica del ordenamiento jurídico que tiene que ser aislada y expulsada del sistema. El estatuto epistemológico iusfilosófico desaparece con Luhmann y, pese a ciertas diferencias sustanciales con el planteamiento de Teubner, similar interpretación puede hacerse de la filosofía del derecho en el paradigma de derecho reflexivo que este último defiende (Teubner, 1993; Bourdieu y Teubner, 2000).

\section{Filosofía del derecho qua Teoría Jurídica}

Quizás uno de los aspectos más polémicos del desdibujamiento de la filosofía del derecho provenga de dos de los autores que, paradójicamente, han sido los que más han invocado su aparente resurrección y categoría. Sin embargo, vistos en profundidad, aunque sin duda reconozcan la importancia de la filosofía del derecho, el uno como ámbito de reflexión para la decisión judicial (Dworkin) y el otro (Alexy) para el que, además, es la Philosophie des Rechts la disciplina que da razón del fenómeno jurídico, lo cierto es que ambos aceleran el proceso de conversión de la filosofía del derecho a la teoría jurídica.

\subsection{Dworkin: derecho como integridad}

Aunque el planteamiento de Dworkin es posterior al de Rawls y, de hecho, explícitamente se inscribe en el giro rawlsiano, su reconocimiento se evidencia en toda su magnitud en su polémica con Hart ${ }^{11}$. El debate giró en torno a la relación entre derecho y moral que, pese a las ambivalencias de su planteamiento, Hart negaría hasta el final mientras que Dworkin defendía una relación estructural entre una y otra, en la medida en que los principios máximos del sistema jurídico resumían, necesariamente también, los principios morales de esa sociedad. Por lo tanto, hablar de dos dimensiones normativas enfrentadas no tenía asidero por cuanto el derecho incorporaba los valores morales de la sociedad a través de sus principios regulativos (Luhmann, 1997, pp.87-119).

No es el caso entrar en los pormenores de esta discusión, sin duda uno de los debates más significativos y representativos de la teoría jurídica contemporánea. El punto es que en el marco de la misma, Dworkin empieza a clasificar esta polémica dentro de la filosofía del derecho y no de la teoría del derecho, seguramente por la introducción de elementos morales y filosóficos en la misma (Dworkin, 1980). Pero con este giro, el desdibujamiento de la filosofía del derecho se vuelve definitivo en la medida en que, como queda claro en toda la obra de Dworkin, la filosofía del derecho, vaciada de sus propios contenidos, es colonizada paradójicamente por los problemas y temáticas de la teoría del derecho, tal como se venían dando desde Kelsen hasta Hart (Dworkin, 1992a). ${ }^{12}$

\footnotetext{
11 (Dworkin y Hart, 1997).

${ }^{12}$ Ver: (Arango, 1999).
} 
[...] los problemas de jurisprudencia son, en lo más profundo, problemas de principios morales, no de hechos legales ni de estrategia [...] Cualquier teoría del derecho competente debe ser ella misma un ejercicio de teoría moral y política normativa [...] La filosofía jurídica no es una disciplina de segundo orden que tenga por objeto el razonamiento jurídico ordinario, sino que ella misma es el nervio de la reflexión sobre el derecho (Dworkin, 1980, p.8).

Esta, sin lugar a dudas, constituye la más paradójica consecuencia del planteamiento dworkiniano cuya pretensión se orientaba, precisamente, a mostrar la imposibilidad de desterrar de la teoría jurídica el problema de los principios y los valores morales como lo había buscado siempre el positivismo. Pero la identificación de esta relectura con la filosofía del derecho, precisamente por ese carácter alterno, lo que hace es desperfilar epistemológicamente a la filosofía del derecho, identificándola con la teoría jurídica:

El análisis dworkiniano del derecho como concepto interpretativo, de acuerdo con el modelo de interpretación del propio Dworkin, hace imposible la filosofía jurídica clásica. En otras palabras, Dworkin desafía la posibilidad y el valor de la "filosofía del derecho general", del intento de analizar las sociedades en sus aspectos más generales (de manera similar al intento por analizar la naturaleza humana) e identificar las características que son comunes a todas las organizaciones sociales que podrían crear la necesidad de establecer instituciones y prácticas similares (en diferentes partes del mundo) (Gavison, 1987).

La iniciativa de Dworkin tiene los efectos contrarios al proyectarse al contexto universal. Su identificación de las problemáticas epistemológicas de la teoría del derecho con las de la filosofía del derecho acelera el reemplazo de los contenidos de la segunda por los de la primera, en una línea similar a la propiciada por el paradigma autopoiético. Dando con ello pie para confundir ambas disciplinas y justificar el que los problemas legales fueran abordados, no desde la teoría jurídica en términos intrasistémicos, sino desde una singular versión de la filosofía del derecho no reconstruida críticamente en términos epistemológicos postconvencionales, sino análoga a la primera, con lo que desdibujó totalmente su naturaleza epistemológica, tanto presente como potencial, incentivando todo tipo de malinterpretaciones sobre el estatuto de las dos.

\subsection{Alexy: validez tríadica del derecho}

Antes de entrar al planteamiento de Habermas, es necesario hacer una digresión en dos sentidos, a partir de la obra de Robert Alexy. La primera hace referencia a la crítica que Alexy le plantea a aquel en cuanto considera que la teoría de la acción comunicativa no puede desconocer el ámbito jurídico y, por tanto, tiene que continuarse como una teoría del derecho. Esta crítica es, sin duda, 
el origen del giro jurídico en el pensamiento de Habermas que lo enfila, desde mediados de los ochenta, hacia lo que terminaría siendo su teoría del estado democrático de derecho en Facticidad y Validez, como se expondrá mas adelante.

Pero además de ello, Alexy desarrolla una interesante propuesta desde la teoría del derecho que constituye un paso adelante en la definición epistemológica de la disciplina. A partir de una crítica de la noción de norma básica normativa en Kant, analítica en Kelsen y empírica en Hart, en cuanto todas presuponen contenidos morales que se niegan a reconocer y que hacen caer sus planteamientos en contradicciones internas, Alexy propone una triádica estructuración de la validez del derecho que integre las diferentes dimensiones que el fenómeno jurídico connota.

La validez del derecho implica, en primer lugar, una validez jurídica que supone que la norma es dictada por órgano competente y según un procedimiento previsto; en segundo lugar, una validez moral, que supone que la norma está moralmente justificada y el sistema posee una pretensión de corrección en caso de normas injustas, y, en tercer lugar, una validez social que supone que la norma vale socialmente porque es obedecida y en caso de desobediencia se aplica una sanción. ${ }^{13}$

Por supuesto, la filosofía del derecho, en su sentido clásico, no tiene cabida en este razonamiento. Por el contrario, constituye una interesante extensión del ámbito de reflexión de la teoría jurídica y la subsunción por parte de ella de los problemas de legitimidad y eficacia en términos de validez moral y validez social del derecho. Con esto, Alexy consagra el estatuto epistemológico de la teoría del derecho que, sin duda, logra con ello dar un paso adelante con relación al resto de disciplinas en cuanto amplía las fronteras de su objeto de estudio sin necesidad de cruzarse con las otras problemáticas.

La asunción que Alexy hace de la filosofía del derecho y su relación con la filosofía en general (Alexy, 2008, pp. 37-38) responde precisamente a una mirada intrasistémica del fenómeno jurídico. La alusión a "filosofía del derecho" tiene que interpretarse en el contexto de una tradición donde paulatinamente los problemas del derecho fueron vistos académicamente desde esta subdisciplina de la filosofía pero, ahora, con un contenido cuyo énfasis es teórico-jurídico:

En la filosofía del derecho, la dimensión analítica se refiere a conceptos como los de norma, "deber ser", persona, acción, sanción e institución. La dimensión sintética se define por el intento de unir estos conceptos en un todo coherente [...] Un panorama coherente y fundado en profundidad [...] es la idea regulativa $[. .$.$] su finalidad última. Esto implica que [...] es necesariamente$

${ }_{13}$ Ver: (Alexy, 1994, pp. 87-122), así como la interesante versión local de (Rodríguez, 1998). 
holística. La filosofía del derecho [...] es una reflexión de índole general y sistemática, y tiene [...] una dimensión normativa, otra analítica y otra holística (35-49).

\section{Reconstrucción de la filosofía del derecho}

\subsection{Rawls: Filosofía de la Justicia}

El resurgimiento de la filosofía moral, política y jurídica en la segunda mitad del siglo XX se origina, cronológicamente, con la publicación de la Teoría de la Justicia (1996) de John Rawls, cuyos planteamientos constituyen un audaz intento por fundamentar una nueva concepción de la moral, la política y el derecho, y de sus relaciones entre sí, con sustanciales connotaciones para el desarrollo institucional de la filosofía moral, jurídica y política contemporáneas. ${ }^{14}$

La Teoría de la Justicia termina así de redondear la crítica al utilitarismo que Rawls había emprendido 20 años atrás, concibiendo un procedimiento de consensualización, la posición original, de la que se derivan, en condiciones simétricas de libertad e igualdad argumentativas, unos principios de justicia que orientan la construcción institucional de la estructura básica de la sociedad, a nivel político, económico y social.

La propuesta rawlsiana subsume, así, tres perspectivas de la razón práctica en tres momentos de un mismo proceso de construcción. Un primer momento, el dialógico-moral que, con la figura de la posición original, supone la obtención de un consenso racional y argumentado donde todas las concepciones de justicia y sus proyecciones económicas son discutidas, contrastadas y asumidas (Mejía, 1996).

Un segundo momento, el político-contractual, donde la concepción política de justicia es fundamentada desde el consenso entrecruzado, las diferentes concepciones omni-comprehensivas razonables de la sociedad y, a partir de ello, se construye cooperativamente, el espacio de lo público. Y, por último, un tercer momento, el ético-contextual, a través del cual la persona o el sujeto colectivo, en el marco de una comunidad y tradición concretas y específicas, subsume o no los principios dentro de su irreductible e irrenunciable esfera particular.

El planteamiento de Rawls, pese al énfasis que parece ponerle a la justicia, bosqueja el nuevo perfil de la filosofía del derecho contemporánea. En efecto, la reflexión rawlsiana involucra y relaciona tres dimensiones en su planteamiento. Una primera, que se deriva de la posición original, es la justificación moral de los principios de justicia. Principios que tienen la pretensión de derivarse de un

\footnotetext{
${ }^{14} \operatorname{Ver}($ Rawls, 1996a); (Rawls, 1996b).
} 
consenso moral que pueda satisfacer a todos por igual sus expectativas mínimas particulares, en condiciones de simetría deliberativa.

Pero esos mismos principios son, a su vez, los criterios de legitimidad del ordenamiento jurídico-político. En efecto, los principios de justicia operan como condiciones de legitimación del sistema en su conjunto en la medida en que las instituciones tienen que adaptarse a los contenidos y prioridades fijados por ellos y, de no hacerlo, la ciudadanía puede acudir a formas de resistencia diversas.

Pero el planteamiento rawlsiano subsume, inmediatamente, una segunda dimensión. Los principios de justicia son externos al ordenamiento pero quedan integrados, tal como lo presenta en la secuencia de cuatro etapas, en un congreso constituyente a través de un principio ya no de legitimidad sino de validez. Principio que después permea las diferentes legislaturas y la administración pública y de justicia $y$, en general, el conjunto de las instituciones. El imperativo consensual de la posición original se recoge en un principio jurídico-constitucional de igual participación que define los términos de validez de las normas jurídicas. Este principio no es ya un criterio de legitimidad política sino un factor de validez jurídica del ordenamiento (Rawls, 1996a, pp.187-192).

La violación de tal principio justifica asumir dos mecanismos que Rawls contempla para que la ciudadanía se oponga a los eventuales excesos de las mayorías legislativas, políticas o sociales: la objeción de conciencia y la desobediencia civil. Estas figuras reivindican el contenido de los principios de justicia, es decir, los criterios de justificación moral y legitimidad política del ordenamiento cuando ha sido violado el factor de validez que el principio de igual participación supone. La legitimidad opera como un regulador sobre la validez (331, ss.).

Pero Rawls introduce una tercera dimensión al abordar el problema de la estabilidad en la tercera parte de su teoría de la justicia. Los principios de justicia y el ordenamiento constitucional que de ellos se ha derivado tienen que ser refrendados desde la cotidianidad de las comunidades. Solo el contraste de la universalidad formal de los principios con la cotidianidad fáctica de las diferentes formas de vida de la ciudadanía que pretende regular garantiza la estabilidad de la sociedad, es decir, en otras palabras, la eficacia social del sistema $(410$, ss.).

Con esto Rawls muestra el nuevo perfil epistemológico de la filosofía del derecho. Sin circunscribirse a la reflexión sobre la justicia como algunos se lo señalaban, casi como un premio de consolación, su planteamiento articula los problemas de la justificación moral, la legitimidad política, la validez jurídica y la eficacia social de un sistema jurídico-político dado. La filosofía del derecho se proyecta entonces como una reflexión integral sobre el derecho que incluye los diversos momentos que configuran el fenómeno jurídico. 


\section{Hacia una teoría crítica del derecho}

\subsection{La sospecha sobre lo jurídico}

Es imprescindible rescatar en este punto los antecedentes de las teorías críticas del derecho desde dos tradiciones de sospecha sobre lo jurídico. Primero, desde la mirada implacable de Marx cuestionando el estatus y la dimensión del derecho que Kant, como expresión última del contractualismo, y Hegel, en su polémica con el anterior, había en todo caso encumbrado en las figuras del contrato social y el estado.

Como se mostró, la tradición marxista, de Marx a Lenin, pasando por Pashukanis y su trascendental debate con Kelsen (Dreier, et al., 1984) ha constituido una radical teoría sobre el derecho, mostrando su estrecha relación con la estructura económica capitalista y denunciándolo como un instrumento de dominación al servicio de la élite burguesa. ${ }^{15} \mathrm{Y}$, segundo, desde la tradición estructuralista, con Foucault básicamente, quien, recuperando la demoledora aunque problemática crítica nietzscheano-heideggeriana al pensamiento occidental, incluyendo el jurídico, concibe el derecho como un instrumento de disciplinización y panoptización social. Dos tradiciones que, pese a sus divergencias, coinciden en una estrategia de sospecha frente al ámbito jurídico, como lo sugirieran sus maestros. ${ }^{16}$

A partir de estas tradiciones de sospecha se constituyen dos vertientes críticas del derecho. La primera vertiente, a mediados de los setenta, se consolida en tres ramificaciones cuestionadoras del derecho contemporáneas (Pérez, 1996, pp.87-102). Estas teorías críticas que además recogen el legado final de la primera Escuela de Frankfurt, se proyectan en tres vertientes: una vertiente italiana, la del Uso Alternativo del Diritto que posteriormente desemboca en el Garantismo y el constitucionalismo radical (Barcelona et al., 1973; Ferrajoli, 1999; Negri, 1994); una francesa, que se manifiesta en el movimiento Critique du Droit que, si bien desaparece, parece resimboliza en una teoría crítica del estado constitucional contemporáneo (Miaille, 1975; Arnaud, 1981; Beaud, 1997); y, finalmente, la norteamericana, en el movimiento de los Critical Legal Studies, la única que sobrevive "oficialmente" y que ha mantenido sus críticas y proyecciones a todos los niveles del derecho (Unger, 1983; Kennedy, 1997 y 1999).

Una segunda vertiente la constituye la heterodoxia socialista, tanto de Europa del Este como del Oeste. Recuperando el espíritu crítico y contestatario del marxismo, la teoría neomarxista, que ya se insinuaba en la primera Escuela de Frankfurt de Horkheimer, Adorno y Marcuse, se materializa en la corriente

\footnotetext{
${ }^{15}$ Ver: (Engels y Marx, 1973); (Lenin, 1971); (Pashukanis, 1976).

${ }^{16}$ Ver: (Foucault, 1976); (Lyotard, 1993); (Derrida, 1997).
} 
del humanismo socialista de la Europa comunista, y asume lentamente el reto de pensar el derecho interdisciplinariamente en el marco de una sociedad postcapitalista globalizada (Adorno y Hokheimer, 1998; Marcuse, 1981; Schaff; 1979).

El humanismo socialista influye, posteriormente, en todo el movimiento postsocialista contemporáneo. La lucha por el reconocimiento (Honneth, 1997), además de un nuevo esquema de justicia distributiva (Heller, 1990) y las sutiles pero determinantes relaciones del derecho (Young, 1990), ya no con la estructura económica sino con la ideología postcapitalista (Jameson, 1991; Berman, 1988) señalan la estrategia proactiva del postsocialismo (Fraser, 1997) y su lucha por ampliar los límites del estado democrático de derecho desde una perspectiva de reconocimiento y no solo de redistribución.

Pero el mérito de estas teorías fue poner de presente la relación estructural que existía entre el derecho y la política y su articulación a través de la decisión judicial, herencia que, en el caso de los CLS, toman del realismo, en sus dos vertientes. Pero al hacerlo, precisamente aunque no de manera expresa, estaban prefigurando el nuevo estatuto epistemológico de la filosofía del derecho: la relación epistemológica de las tres dimensiones de la legitimidad, la validez y la eficacia que, más tarde con Habermas alcanzarían su máximo desarrollo sistemático.

Vale la pena destacar en esa línea el movimiento Crítica del Derecho francés, en su momento encabezado por Miaille y Arnaud. La intención explícita del movimiento fue reconstituir el estatuto epistemológico de la teoría jurídica, desbordando los marcos convencionales que el positivismo le había fijado. Allí se hizo evidente un programa de investigación que buscaba superar el formalismo del derecho moderno, poniendo de presente los supuestos económicos y políticos sobre los que descansaba la validez formal del sistema jurídico, así como los términos capitalistas que su eficacia perseguía.

Aunque su pretensión se inscribía estrictamente en la recomposición epistemológica de la teoría jurídica los alcances de su planteamiento de hecho problematizaban sus propios límites, prefigurando el nuevo estatuto de la filosofía del derecho. En ese sentido, el movimiento adquiere más proyección que los mismos CLS actuales, no así de los fundadores del movimiento que tenían mas clara la relación epistemológica global que debían asumir (Unger, 1983), pero sí de sus continuadores que parecen circunscribirse a los procesos de decisión y adjudicación judicial, estrictamente, perdiendo el horizonte transdisciplinar de la relación. 
El movimiento postsocialista incentiva esta tendencia, si bien su reflexión no pretende inscribirse ni en la teoría jurídica ni en la filosofía del derecho. Pero su abordaje de problemas sociales periféricos y su reconocimiento de que sean articulados en términos del sistema jurídico fortalecen la relectura epistemológica que aquí ha querido hacerse de una nueva filosofía del derecho y que, de alguna manera, Habermas llevará a su expresión sistemática más acabada.

\subsection{Habermas: teoría discursiva del derecho}

El pensamiento de Habermas puede interpretarse como una propuesta integral de filosofía práctica en tres direcciones que, a su vez, constituyen tres etapas en el desarrollo del mismo. En una primera etapa, Habermas propugna por redefinir los nuevos términos de la problemática filosófico-política en el capitalismo tardío, derivando de ello un proyecto de reconstrucción del materialismo histórico así como asignándole a la filosofía un nuevo papel en el contexto de ello (Habermas, 1992, pp.131-167). En una segunda etapa, su reflexión se centra en la fundamentación de una teoría de la acción comunicativa como estrategia central de relegitimación de la sociedad capitalista, a partir de un agudo e implacable diagnóstico de la colonización que sobre el mundo de la vida ha ejercido el derecho, generando un proceso de desintegración acelerada a su interior. Estrategia que Habermas complementa con la concepción de su ética discursiva, inmediatamente después (Habermas, 1989, 1991a).

Ante las críticas de Robert Alexy en cuanto que la propuesta habermasiana no podía seguir ignorando en su estrategia de solución el derecho como instrumento, Habermas inicia lo que puede denominarse el giro jurídico hacia la reconsideración proactiva del estado de derecho, que, en un primer momento, lo lanza hacia el iuspositivismo y cuya tensión entre legalidad y legitimidad resuelve con la procedimentalización de la soberanía popular (Habermas, 1991b, pp. 131 172; Habermas, 1990a).

En el marco de este giro, Habermas desarrolla, en la tercera etapa de su monumental reflexión, una teoría del derecho y la democracia que, de una parte, profundiza sus reflexiones tempranas sobre la legitimación en el capitalismo tardío que le permite replantear y complementar su propia teoría de la acción comunicativa y, de otra, en diálogo con las principales corrientes iusfilosóficas, socio-jurídicas, teórico-jurídicas y filosófico-políticas contemporáneas, proponer un nuevo paradigma jurídico-político, el discursivo-procedimental, cuyo objetivo es superar la crisis de las sociedades contemporáneas a través de la reconstrucción normativa de la legitimidad fracturada, conciliando la dicotomía entre el mundo de la vida y los subsistemas económico y político-administrativo a través de un modelo de democracia deliberativa como expresión del poder comunicativo de la sociedad civil y la opinión pública (Habermas, 1998). 
Obviamente, Habermas ha replanteado desde muy temprano el papel que a la filosofía le cabe en cuanto pensamiento postmetafísico. En un escrito temprano ya señalaba en qué sentido la filosofía clásica no podía definirse sino como teoría crítica social y en sus escritos tardíos ha insistido en los cambios radicales que la reflexión filosófica debe asumir hacia el futuro en especial en lo que tiene que ver con el abandono del logocentrismo del pensamiento moderno, reorientado por el giro lingüístico hacia un nuevo tipo de racionalidad procedimental, el carácter situado que la razón postmetafísica adquiere y la inversión del primado de la teoría sobre la praxis, características todas que redefinen el papel contemporáneo de la filosofía. ${ }^{17}$

En ese contexto podría pensarse que la filosofía del derecho no tendría un estatuto especial más que como intérprete de una tradición jurídica y vigilante de unos procesos de racionalidad al interior del derecho. $\mathrm{Y}$ si bien en Facticidad y Validez, Habermas denuncia, precisamente hablando de Rawls, la impotencia kantiana en que puede caer la filosofía de la justicia, y de que su planteamiento iusfilosófico pretende es resolverse en el plano de la teoría jurídica e, incluso, de la teoría constitucional, sin duda alguna las derivaciones de su teoría del estado democrático de derecho constituyen, en una dirección similar a la de Rawls, la perfilación de un nuevo estatuto epistemológico para la filosofía del derecho. ${ }^{18}$

En efecto, Habermas relaciona y articula de manera complementaria e integral tres dimensiones que la filosofía práctica y el pensamiento social habían disgregado: el de la legitimidad política (incluido en ella el de la justificación moral), la validez jurídica y la eficacia social. El estado democrático de derecho como categoría iusfilosófica supone tres momentos que deben ser considerados en su autonomía, por supuesto, pero también en su interdependencia recíproca. Por su posición omnimediadora en la sociedad moderna, el derecho es el único instrumento y el ámbito social exclusivo desde el cual replantear la integración social y reconstruir los presupuestos de legitimidad que fundamenten de nuevo el lazo social desintegrado.

El derecho debe ser, pues, concebido como la categoría de mediación social entre hechos y normas o, en otras palabras, entre el mundo de la vida y los subsistemas funcionales económico y político-administrativo. La tensión entre facticidad y validez, entre legalidad y legitimidad, entre los ámbitos mundo-vitales y sistémicos sólo puede resolverse, en un mundo desencantado postindustrial, a través del derecho, exclusivamente. Así, el fundamento ontológico es la consideración del derecho como medium de la integración social y el fundamento epistemológico es la consideración del derecho como categoría de la integración social. ${ }^{19}$

\footnotetext{
17 Ver: (Habermas, 1982, pp. 62-88); (Habermas, 1991c, pp. 9-29); y (Habermas, 1990b, pp. 11-63).

${ }^{18}$ En idéntica línea aunque con un título que sugeriría lo contrario ver Velasco, 2000.

19 (Habermas, 1982, pp. 130-145).
} 
En una línea de razonamiento similar a la de Rawls, Habermas va a definir el estado democrático de derecho desde tres dimensiones que, simultáneamente, permitirán redefinir el papel de la filosofía del derecho. Una primera dimensión especifica los términos de legitimidad política del estado democrático de derecho a partir de la consideración de una soberanía popular plural, no hipostasiada jurídicamente.

El ordenamiento es legítimo cuando las diversas formas de vida y sujetos colectivos que conforman la ciudadanía en una sociedad democrática crean poder comunicativo a través del diálogo entre ellos. Lo anterior supone una justificación moral que no es, en últimas, más que la aplicación del principio de argumentación moral a los procesos de formación de opinión y voluntad públicas. La legitimidad, entendida como soberanía popular plural a través de procesos deliberativos, tiene, pues, un sustento en la racionalidad dialógica de una sociedad democrática.

La racionalidad dialógica que, en último término, se satisface en la realización del ideal normativo de una situación ideal del habla constituye la condición de una argumentación plenamente racional y, según Habermas, permite encontrar el principio de legitimidad en el diálogo. Este principio es el mismo principio de la democracia, el cual se define por un principio dialogal de legitimación. El diálogo es, pues, lo que posibilita la reconstrucción normativa de la legitimidad y en tal medida esta se encuentra en la comunicación y argumentación libre de coacción externa, en el marco de unas condiciones que permitan el entendimiento, objetivo central del lenguaje.

En otras palabras, en la democracia los procedimientos adquieren fuerza legitimadora en la medida en que vienen mediados por un procedimiento de consensualización que ha definido previamente su dimensión normativa. Es gracias a esta comunicación no coaccionada que, a través del diálogo, llega a un entendimiento que se produce la formación discursiva de la voluntad colectiva. De aquí que la democracia se fundamente normativamente en un principio consensual de legitimación.

Aquí enlaza Habermas la segunda dimensión: la de la validez jurídica del estado democrático de derecho. El derecho moderno tiene un doble rostro de Jano: por un lado acomete funciones estratégico-sistémicas y por otro integra socialmente a la ciudadanía en su conjunto. Ello se realiza a través de procedimientos democráticos institucionalizados que constituyen la única fuente postconvencional de legitimidad en las sociedades complejas.

Esta complejidad, precisamente, impone la necesidad de superar los esquemas contractualistas — basados en meros acuerdos de intereses- por esquemas dialógicos que garanticen consensos normativos amplios. El principio discursivo, 
aplicado al derecho, desarrolla un paradigma procedimental que privilegia las condiciones comunicativas y los procesos de formación de la opinión y la voluntad públicas y que, en su aplicación, es el único que asegura la autonomía moral de los diversos sujetos colectivos ciudadanos. ${ }^{20}$

Esto se impone en la medida en que sólo el derecho positivo asegura la autonomía como no puede hacerlo la moral en las sociedades complejas. En efecto, la ley debe ser la expresión simultánea de la elección racional de actores libres y la elección existencial de personas. La autonomía legal afianza a un tiempo las libertades individuales y las comunicativas y ello demuestra la complejización que la estructura del derecho ha sufrido frente a la de la moral en la medida en que, primero, regula y libera los límites de acción de la libertad individual $y$, segundo, incorpora objetivos colectivos que sobrepasan las consideraciones morales individuales.

La tercera dimensión del estado democrático de derecho es la de la eficacia social del ordenamiento. ¿En qué medida es eficaz un orden social? Para Kelsen, la validez jurídica requería un mínimo de eficacia y ello tenía como condición que la conducta que el sistema jurídico buscaba prescribir fuera mínimamente congruente con la comunidad que aspiraba a regular de tal suerte que su pretensión prescriptiva fuera compatible con el modus vivendi de esa comunidad.

En Hart, si bien la validez está determinada por una regla de reconocimiento en lo esencial definida por el punto de vista interno de un sistema jurídico, esta perspectiva supone la legitimidad y la eficacia que solo el punto de vista externo puede reconocer. Luhmann, como se vio, resuelve este problema reduciendo la eficacia social, así como la legitimidad política, a una dimensión autorreferencial de validez jurídica que en la medida en que permite que el sistema jurídico se adapte a su propia complejidad, se legitima sistémicamente y posibilita la reducción de complejidad social, siendo así eficaz.

En una línea similar, el estado democrático de derecho es eficaz en la medida en que es legitimo políticamente, lo que supone una dimensión de justificación moral, y válido jurídicamente, lo que a su vez supone que satisfaga unas expectativas de validez social, es decir, que posibilite la integración de los diferentes sujetos colectivos de la sociedad en su conjunto, y unas expectativas de validez instrumental, es decir, que posibilite la integración sistémica de los diferentes sistemas sociales de la sociedad en general.

La eficacia del estado democrático de derecho se define, así, en una soberanía popular procedimentalizada discursivamente a través de un catálogo de derechos fundamentales que garantiza su legitimidad política y propicia su validez

20 (Habermas, 1982, pp. 90-103). 
jurídica, en los términos señalados. El paradigma discursivo-procedimental que fundamenta el ordenamiento se proyecta en términos de un modelo alternativo de democracia deliberativa donde el poder comunicativo de la sociedad civil deviene poder administrativo del estado. ${ }^{21}$

La dicotomía entre derechos-libertades y derechos-sociales se supera en términos de derechos-participación: la democratización de la democracia permite que los procedimientos se legitimen y sirvan no a una lógica procedimentalsistémica sino a la más amplia deliberación de la sociedad toda en la perspectiva de asegurar que la influencia política de la opinión pública, expresión del poder comunicativo de la sociedad civil, devenga efectivamente poder administrativo instrumental. ${ }^{22}$

Recuperado el carácter interdisciplinario de la primera teoría crítica y la línea de una teoría social como horizonte de la reflexión filosófica, así como rescatando — sin lugar a dudas - los desarrollos tanto del movimiento humanista del socialismo de Europa del Este como los presupuestos y proyecciones de las teorías críticas del derecho de los sesenta, Habermas permite redefinir el estatuto epistemológico de la filosofía del derecho desde la consideración integral, intra y suprasistémica, de las dimensiones de legitimidad, validez y eficacia que el abordaje del estado democrático de derecho contemporáneo supone.

\section{Conclusión}

La reconstrucción epistemológica de la filosofía del derecho que aquí se ha intentando bosquejar ha puesto de presente dos factores en ese propósito. El primero, el proceso de ruptura y desdibujamiento de la filosofía del derecho que se da con el surgimiento y consolidación de la teoría jurídica a partir del positivismo en el siglo XX. Y, el segundo, la recuperación de las nuevas reflexiones que sobre el derecho se han venido haciendo en el último cuarto del siglo $X X$, partiendo de Rawls y terminando con Habermas, y mostrando en el intermedio los impulsos que en tal sentido ya se prefiguraban en las teorías críticas del derecho y el pensamiento postsocialista por repensar y recomponer transdisciplinariamente su estatuto propio.

¿Qué se deriva de todo lo anterior para el estatuto epistemológico de la filosofía del derecho? Sin duda el punto más decisivo tiene que ver con la problemática propia a la disciplina, disputada y desmembrada por la filosofía política, la teoría del derecho y la sociología jurídica, entre otras, que reclaman para sí el abordaje de la legitimidad, la validez y la eficacia, en sus diferentes proyecciones. Los planteamientos de Rawls y Habermas dan la clave de bóveda de esta reconsideración de la problemática propia de la filosofía del derecho.

\footnotetext{
${ }^{21}$ (Habermas, 1982, pp. 184-197).

22 (Habermas, 1982, pp. 421-439).
} 
Queda claro en esta reconstrucción histórica — preámbulo analítico de una estructural desarrollada en otros escritos ${ }^{23}$ — que la filosofía del derecho responde a una tradición filosófica y no teórico-jurídica y, por lo tanto, se enmarca en los límites y problemáticas de la filosofía práctica y no de la teoría jurídica. La teoría jurídica ha logrado enormes avances en cuanto a su definición epistemológica e, indudablemente, jalona con ello al conjunto de subdisciplinas filosóficas y disciplinas sociales. La estructuración triádica de su problemática particular tiene que ser reivindicada como un logro epistemológico significativo que la reflexión jurídica tiene que asumir y profundizar sin necesidad de acudir a la filosofía, ni de confundir teoría jurídica y filosofía del derecho (Alexy, 1994, pp. 87-122). ${ }^{24}$

Mientras que la teoría jurídica pone el acento en la validez del sistema jurídico, la filosofía del derecho necesariamente tiene que abordar toda la complejidad intra y suprasistémica del ordenamiento jurídico. De allí que tenga que abarcar igualmente problemáticas propias de la filosofía política y la sociología jurídica, articulando así en una visión totalizante y crítica la relación legitimidad-validez-eficacia de un ordenamiento jurídico-político como eje vertebral de su reflexión epistemológica. De tal suerte, frente a la mirada disciplinaria de la teoría jurídica, la filosofía del derecho se presenta como la visión transdisciplinaria del fenómeno jurídico (D’Ágostini, 2000, pp. 481-542).

En ese orden, creo haber ilustrado la hipótesis de trabajo que este escrito buscó ilustrar, a saber:

La distinción epistemológica entre filosofía del derecho y teoría jurídica se justifica históricamente en cuanto la primera responde a una tradición filosófica, que alcanza su apogeo con lo modelos de Kant y Hegel, mientras que la segunda se inscribe en una tradición jurídica (que, análogamente, se consagra a partir de Kelsen), siendo cada cual una disciplina autónoma que no puede confundirse con la otra pues cada una posee dominios epistémicos diferentes. Sin embargo, el estatuto epistemológico de la primera puede ser reconstruido en diálogo con la teoría jurídica y la teoría constitucional, relacionando transdisciplinariamente las tres problemáticas de la legitimidad, la validez y la eficacia desde una teoría crítica del derecho que permita articular una visión sistemática, cuestionadora y totalizante del fenómeno jurídico en su complejidad integral $\varphi$

\footnotetext{
${ }^{23}$ Ver: (Mejía, 2003).

${ }^{24}$ No tomo en cuenta su conferencia reciente La Naturaleza de la Filosofía del Derecho (2003, Bogotá, Universidad Externado de Colombia) que, desde la perspectiva defendida en este escrito, versaría más sobre la naturaleza de la teoría jurídica.
} 


\section{REFERENCIAS}

Adorno, T. y Hokheimer, M. (1998). Dialéctica de la llustración. Madrid: Trotta.

Alexy, R. (1994). "La validez del derecho". Concepto y Validez del Derecho. Barcelona: Gedisa.

Alexy, R. (2003). "La Naturaleza de la Filosofía del Derecho". Conferencia presentada en Bogotá, Universidad Externado de Colombia.

Alexy, R. (2008). "La naturaleza de la filosofía del derecho". El Concepto y la Naturaleza del Derecho. Madrid: Marcial Pons.

Althusser, L. (1974). Ideología y Aparatos Ideológicos de Estado. Bogotá: Tupac Amaru.

Arango, R. (1999). ¿Hay respuestas correctas en el Derecho? Bogotá: Siglo del Hombre-Ediciones Universidad de los Andes.

Aristóteles (1987). Ética a Nicómaco. Madrid: Espada-Calpe.

Arnaud, A. (1981). Critique de la Raison Juridique. París: L.G.D.J.

Barcelona, P., et al. (1973). L'Uso Alternativo del Diritto. Roma: Laterza.

Beaud, J. (1997). La Puissance del l'Etat. París: PUF.

Berman, M. (1988). Todo lo Sólido se Desvanece en el Aire. México: Siglo XXI.

Bourdieu, P. y Teubner, G. (2000). La fuerza del derecho. Bogotá: Siglo del Hombre Editores.

Conde, R. (1989). Pashukanis y la Teoría Marxista del Derecho. Madrid: C.E.C.

Cortina, A. (1989). "Aportaciones de La Metafísica de las Costumbres". La Metafísica de las Costumbres. Bogotá: REI.

D’Ágostini, F. (2000). Analíticos y continentales. Madrid: Cátedra.

Del Vecchio, G. (1991). "Concepto y temas de la filosofía del derecho". Filosofía del Derecho. Barcelona: Bosch.

Derrida, J. (1997). Fuerza de Ley. Madrid: Tecnos. 
Dreier, R., et al. (1984). Teoría Pura del Derecho y Teoría Marxista del Derecho. Bogotá: Témis.

Dworkin, R. (1980). La filosofía del Derecho. México: Fondo de Cultura Económica.

Dworkin, R. (1992a). Los Derechos en Serio. Barcelona: Gedisa.

Dworkin, R. y Hart, H.L.A. (1997). La Decisión Judicial. Bogotá: Siglo del HombreEdiciones Universidad de los Andes.

Engels, F. y Marx, K. (1973). Obras Escogidas. Moscú: Progreso.

Fernández, E. (1991). Teoría de la Justicia y Derechos Humanos. Madrid: Debate.

Ferrajoli, L. (1999). Derechos y Garantías. Madrid: Trotta.

Findlay, J. (1969). Reexamen de Hegel. Barcelona: Grijalbo.

Foucault, M. (1976). Vigilar y Castigar. México: Siglo XXI.

Fraser, N. (1997). Iustitia Interrupta. Bogotá: Siglo del Hombre-Ediciones Universidad de los Andes.

Gavison, R. (1987). Issues in Contemporary Legal Philosophy. Oxford: Clarendon Press.

Giménez, P. (1993). El Derecho en la Teoría de la Sociedad de Niklas Luhmann. Barcelona: Bosch Editor.

González, F. (1984). "El principio de autonomía y el concepto del derecho". De Kant a Marx. Valencia: Fernando Torres.

Habermas, J. (1982). Sobre Nietzsche y otros Ensayos. Madrid: Tecnos.

Habermas, J. (1989). Teoría de la Acción Comunicativa. Buenos Aires: Taurus.

Habermas, J. (1990a). "Soberanía popular como procedimiento". Revista Foro (12).

Habermas, J. (1990b). "Retorno a la metafísica". Pensamiento Postmetafísico. Madrid: Taurus.

Habermas, J. (1991a). Conciencia Moral y Acción Comunicativa. Barcelona: Península. 
Habermas, J. (1991b). "Cómo es posible la legitimidad vía de legalidad\#. Escritos sobre Moralidad y Eticidad. Barcelona: Paidós.

Habermas, J. (1991c). "La filosofía como vigilante e intérprete" en Conciencia Moral y Acción Comunicativa. Barcelona: Península.

Habermas, J. (1992). La Reconstrucción del Materialismo Histórico. Madrid: Taurus. Habermas, J. (1998). Facticidad y Validez. Madrid: Trotta.

Hart, H.L.A. (1995). El concepto de Derecho. Buenos Aires: Abeledo-Perrot.

Hegel, F. (1968). Filosofía del Derecho. Buenos Aires: Claridad.

Heller, A. (1990). Más Allá de la Justicia. Barcelona: Crítica.

Hernández, R. (1989). Historia de la Filosofía del Derecho Contemporánea. Madrid: Tecnos.

Hierro, L. (1996). "Realismo jurídico". El Derecho y la Justicia. Madrid: Trotta.

Honneth, A. (1997). La Lucha por el Reconocimiento. Barcelona: Crítica.

Izuzquiza, I. (1990). La sociedad sin hombres. Barcelona: Anthropos.

Jameson, F. (1991). El Posmodernismo. Barcelona: Paidós.

Kaufmann, A. (1999). "Naturaleza, tareas y posición sistemática de la filosofía del derecho". Filosofía del Derecho. Bogotá: Universidad Externado.

Kelsen, H. (1996). Introduction to the Problems of Legal Theory. Oxford: Clarendon Press.

Kelsen, H. (1997). Teoría Pura del Derecho. México: Porrúa.

Kennedy, D. (1997). A Critique of Adjudication. Cambridge: Harvard University Press.

Kennedy, D. (1999). Libertad y Restricción en la Decisión Judicial. Bogotá: Siglo del Hombre Editores.

Lenin, V. (1971). El Estado y la Revolución. Pekín: E.L.E.

Luhmann, N. (1985). A Sociological Theory of Law. London: Routledge \& Kegan. 
Luhmann, N. (1997). Observaciones de la Modernidad. Barcelona: Paidós.

Lyotard, J.F. (1993). La condición Postmoderna. México: REI.

Marcuse, H. (1976). "La filosofía política". Razón y Revolución. Madrid: Alianza.

Marcuse, H. (1981). El Hombre Unidimensional. Barcelona: Ariel.

Martínez, J. (1992). La imaginación Jurídica. Madrid: Debate.

Marx, K. (1973). "Prólogo de la Contribución a la Crítica de la Economía Política". Obras Escogidas. Moscú: Editorial Progreso.

Marx. K (1978). Crítica de la Filosofía del Derecho de Hegel. Bogotá: Editorial Eris.

Mazurek, P. y Kaufmann, A. (Eds.), (1992). "Teoría marxista y socialista del derecho" El Pensamiento Jurídico Contemporáneo. Madrid: Editorial Debate.

Mejía, O. (1996). "El paradigma consensual del derecho en la teoría de la justicia de John Rawls". Bogotá: Facultad de Derecho Universidad de los Andes.

Mejía, O. (1997). "La tradición contractualista". Justicia y Democracia Consensual. Bogotá: Siglo del Hombre-Ediciones Universidad de los Andes.

Mejía, O. (2003). Legitimidad, Validez y Efricacia. Prolegómenos para una Reconstrucción del Estatuto Epistemológico de la Filosofía del Derecho. Bogotá: Editorial Universidad Nacional de Colombia.

Miaille, M. (1975). Une Introduction Critique au Droit. París: Maspero.

Naranjo, A. (1992). Filosofía del Derecho. Bogotá: Témis.

Negri, A. (1994). El Poder Constituyente. Madrid: Prodhufi.

Palmier, J.M. (1977). Hegel. México: Fondo de Cultura Económica.

Pashukanis, E. (1976). Teoría General del Derecho y Marxismo. Barcelona: Labor.

Pérez, J. (1996). Garzón, E. y Laporta, F. (Eds.), "Teorías críticas del derecho". El Derecho y la Justicia. Madrid: Trotta.

Poulantzas, N. (1976). Poder Político y clases sociales en el Estado capitalista. México: Siglo XXI. 
Rawls, J. (1996a). Teoría de la Justicia. México: Fondo de Cultura Económica.

Rawls, J. (1996b). Liberalismo Político. Barcelona: Crítica.

Radbruch, G. (1993). "Algunos problemas actuales de la filosofía del derecho". Introducción a la Filosofía del Derecho. México: Fondo de Cultura Económica.

Rodríguez, A. (1998). "Unidad y validez de los sistemas jurídicos". Revista Examen (1).

Robles, G. (1993). "La teoría del derecho como sustitución de la filosofía del derecho". Introducción a la Teoría del Derecho. Madrid: Debate.

Schaff, A. (1979). La Alienación como Fenómeno Social. Barcelona: Crítica.

Schmitt, C. (1996). Sobre los Tres Modos de Pensar la Ciencia Jurídica. Madrid: Tecnos.

Teubner, G. (1993). Le Droit un Systeme Autopoiétique. París: PUF.

Unger, R. (1983). The Critical Legal Studies Movement. Cambridge: Harvard University Press.

Velasco, J. (2000). La Teoría Discursiva del Derecho. Madrid: C.E.C.

Young, I. (1990). Justice and the Politics of Difference. Princeton: Princeton University Press. 